\title{
Water adsorption on polycrystalline vanadium from ultra-high vacuum to ambient relative humidity
}

\author{
C. Rameshan ${ }^{\mathrm{a} *}$, M.L. Ng $^{\mathrm{b}}$, A. Shavorskiy ${ }^{\mathrm{c}}$, J.T. Newberg $^{\mathrm{d}}$, H. Bluhm ${ }^{\mathrm{c}}$ \\ ${ }^{a}$ Institute of Materials Chemistry, Vienna University of Technology, Getreidemarkt 9, 1060 Vienna, \\ Austria \\ ${ }^{b}$ SUNCAT Center for Interface Science and Catalysis, SLAC National Accelerator Laboratory, Menlo \\ Park CA 94025, USA. \\ ${ }^{\mathrm{c}}$ Chemical Sciences Division, Lawrence Berkeley National Laboratory, Berkeley, CA 94720, USA \\ ${ }^{\mathrm{d}}$ Department of Chemistry \& Biochemistry, University of Delaware, Newark, DE 19716, USA \\ *Corresponding author: christoph.rameshan@tuwien.ac.at
}

\begin{abstract}
We have studied the reaction of water vapor with a polycrystalline vanadium surface using ambient pressure X-ray photoelectron spectroscopy (AP-XPS) which allows the investigation of the chemical composition of the vanadium/water vapor interface at $\mathrm{p}\left(\mathrm{H}_{2} \mathrm{O}\right)$ in the Torr range. Water dissociation on the vanadium surface was studied under isobaric conditions at $\mathrm{p}\left(\mathrm{H}_{2} \mathrm{O}\right)$ ranging from 0.01 to 0.50 Torr and temperatures from $625 \mathrm{~K}$ to $260 \mathrm{~K}$, i.e. up to a relative humidity $(\mathrm{RH})$ of $\sim 15 \%$. Water vapor exposure leads to oxidation and hydroxylation of the vanadium foil already at a pressure of $1 \times 10^{-6}$ Torr at $300 \mathrm{~K}\left(\mathrm{RH} \sim 4 \times 10^{-6}\right.$ $\%)$. The vanadium oxide layer on the surface has a stoichiometry of $\mathrm{V}_{2} \mathrm{O}_{3}$. Initial adsorption of molecular water on the surface is observed at $\mathrm{RH}>0.001 \%$. Above a $\mathrm{RH}$ of $0.5 \%$ the amount of adsorbed water increases markedly. Experiments at increasing temperatures show that the water adsorption process is reversible. Depth profile measurements show a thickness for the vanadium oxide layer of 3-5 mono layers (ML) and for vanadium hydroxide of 1-1.5 ML over the whole RH range in the isobar experiments. The thickness of the adsorbed water layer was found to be in the sub-ML range for the investigated RH's.
\end{abstract}

Keywords: Hydroxylation, ambient pressure photoelectron spectroscopy, water adsorption, Vanadium, in-situ spectroscopy 


\section{Introduction}

The interaction of water vapor with solid surfaces at ambient conditions of temperature and relative humidity plays a major role in technological applications and in the environment and is thus a highly interdisciplinary field. Hitherto research has focused on the role of interfacial water in heterogeneous catalysis[1-3], atmospheric chemistry[4, 5], environmental science[6], corrosion chemistry[7] and electrochemistry[8, 9]. The mechanism and kinetics of surface chemical processes are strongly influenced by the presence of adsorbed water[10, 11]. Water can be a participant or product in surface chemical reactions, as in the water gas shift reaction $\left(\mathrm{CO}+\mathrm{H}_{2} \mathrm{O} \rightarrow \mathrm{CO}_{2}+\mathrm{H}_{2}\right)$ or it can be a spectator and still influence the reaction through blocking of active sites or hindering the adsorption of reactants. On the other hand, trace amounts of $\mathrm{H}_{2} \mathrm{O}$ can promote $\mathrm{CO}$ oxidation on $\mathrm{Pt}(111)[12]$ and $\mathrm{Au}$ nanoparticles supported on $\mathrm{TiO}_{2[13,14]}$. Most surfaces, in particular the polar ones, are covered by a water layer with thicknesses from a few $\AA$ (aerosol particles in troposphere) to infinite thickness (particles in solution) under ambient relative humidities[15-17]. Despite its importance the growth mechanism of water and water layers on different materials (metallic, mineral, oxide) is still not fully understood for all surfaces.

The interaction of water with solid surfaces has been intensively studied by using surface science techniques in ultrahigh vacuum (UHV) and at low temperatures. These studies provide detailed information on the water/solid interface at a molecular level[18-20]. Most processes of interest in real systems take place at elevated temperatures and at ambient or even higher pressures, as in heterogeneous catalysis. The fundamental question is if the information that is gained under UHV and low temperatures can be extrapolated to realistic conditions. The structure and chemical composition of the surface in equilibrium with gases at ambient pressure can be different from those in UHV. Furthermore, chemical reactions can be kinetically hindered at low temperatures. This is often referred to as the "pressure gap". In order to close this gap, surface chemical reactions - including those involving water - have to be investigated in situ at as close to realistic operating conditions as possible.

Synchrotron based in situ ambient pressure XPS (AP-XPS) is an excellent experimental tool for water adsorption studies on surfaces at ambient relative humidities since it allows the investigation of surfaces at water vapor pressures in the Torr range (equilibrium water vapor pressure at $273 \mathrm{~K}$ is 4.6 Torr) and up to a $\mathrm{RH}$ of $100 \%$ [21]. Furthermore it provides information on the elemental composition at the sample surface as well as on the local chemical environment (e.g., oxidation states and functional groups)[22]. Recently, APXPS has been used to investigate the interaction of water with $\mathrm{Cu}$ metal[23] and metal oxide 
surfaces, including $\alpha-\mathrm{Fe}_{2} \mathrm{O}_{3}(0001)[24], \mathrm{Fe}_{3} \mathrm{O}_{4}(001)$ [25], $\mathrm{MgO}(100) / \mathrm{Ag}(100)$ [26], $\mathrm{Cu}_{2} \mathrm{O}$ [27], $\mathrm{Al}_{2} \mathrm{O}_{3[27]}, \mathrm{TiO}_{2}[15]$ and $\mathrm{SiO}_{2}[28]$. Here we discuss the interaction of water vapor with a polycrystalline vanadium surface.

Vanadium is used in a wide range of applications. Aside from steel production, vanadium metal is used as a coating material, an alloy component in functional materials[29] and it is also a promising alternative to more costly metals (such as $\mathrm{Pd}$ ) in $\mathrm{H}_{2}$ purification processes[30]. Vanadium oxides are part of electrical and optical switching devices, light detectors, sensors and in heterogeneous catalysis. The high variety of oxidation states of vanadium $\left(\mathrm{V}^{0}-\mathrm{V}^{5+}\right)$ make it suitable for numerous catalytic reactions $[31,32]$.

Extended research has focused on the properties of vanadium oxide, as described in the review of Surnev et al.[33]. There is, however, not much information yet on the interaction of vanadium metal with water vapor, although this is highly relevant for hydrogen purification processes, including vanadium membranes, and for catalytic reactions. Jaeger et al.[34] studied the chemisorption of water on vanadium clusters by infrared photodissociation (IR-PD) spectroscopy. On the basis of their measurements they postulated that on the $\mathrm{V}^{+}-$ clusters (3 to 18 atoms) water is mainly adsorbed as intact molecule; it could not be excluded, however, that some dissociative chemisorption of water is present on the clusters because hydroxyl groups would not exhibit any bending mode resonance in IR-PD[34].

Here we report on the interaction of water vapor with a polycrystalline vanadium foil, which we have studied using AP-XPS by measuring uptake and desorption isobars at water pressures of $0.05,0.10,0.25$ and 0.50 Torr. The quantitative analysis of the peak areas due to adsorbed water molecules, hydroxide groups and vanadium oxide provides information on the degree of oxidation and hydroxylation of the vanadium surface as well as the thickness of the adsorbed water layer as a function of RH. We show that hydroxylation occurs at $\mathrm{RH}<10^{-6} \%$, while molecular water is already present at $\mathrm{RH}$ as low as $10^{-3} \%$. These results imply that the vanadium surface is covered by a significant amount of hydroxyl groups and molecular water molecules under most realistic operating conditions, which need to be taken into account in models of the heterogeneous surface chemistry of vanadium in catalytic reactions.

\section{Materials and Methods}

The experiments were performed at the Molecular Environmental Science beamline (11.0.2) at the Advanced Light Source (ALS) at Lawrence Berkeley National Laboratory[21], using the ambient pressure X-ray photoelectron spectrometer endstation[35]. AP-XPS is based on a differentially-pumped electrostatic lens system, which minimizes the path length 
of electrons through the high-pressure region and thus scattering of electrons by gas molecules, as well as maintains high vacuum conditions in the electron energy analyzer[21, 36].

Polycrystalline vanadium foil (Alfa Aesar, 99.5\% purity, $0.15 \mathrm{~mm}$ thickness) was cleaned prior to the experiments by several sputter-anneal cycles $\left(10^{-5}\right.$ Torr of Ar, $1.5 \mathrm{keV}, 4$ $\mathrm{mA}$ ) followed by annealing to $1200 \mathrm{~K}$ for two minutes. The cleaning progress was monitored by XPS. All impurities could be removed except for small traces of oxygen (less than $\sim 0.15$ ML equivalent, chamber base pressure was $\sim 8 \times 10^{-10}$ Torr). The high reactivity of vanadium towards oxygen and water vapor in the residual gas makes the preparation of oxygen-free surfaces extremely difficult. The required equipment for the preparation of oxygen-free vanadium, a titanium sublimation pump and a cooling trap held at liquid nitrogen temperature as it is described in the literature[37], is not compatible with the experimental setup used in the present investigations.

After cleaning, the vanadium foil was transferred from the preparation chamber to the spectroscopy chamber for XPS analysis of the initial state of the foil prior to water vapor exposure. XPS data were collected for V 2p, O 1s and C 1s core levels at a kinetic energy (KE) of $\sim 210 \mathrm{eV}$ with incident photon energies of $720 \mathrm{eV}, 735 \mathrm{eV}$ and $490 \mathrm{eV}$, respectively. For the depth profiling the $\mathrm{O} 1 \mathrm{~s}$ and $\mathrm{V} 2 \mathrm{p}$ spectra were taken in sequence with kinetic energies between $115 \mathrm{eV}$ and $715 \mathrm{eV}$ in $100 \mathrm{eV}$ increments. All binding energies were referenced to the V Fermi edge, which was measured after every change of the incident photon energy.

Water vapor from HPLC grade water was introduced into the measurement chamber through a precision leak valve. Prior to the experiments the water was purified in multiple freeze-pump-thaw cycles followed by direct pumping on the water source at room temperature. The relative humidity is defined by $\mathrm{RH}=100\left(p / p_{0}\right)$, where $p$ is the water vapor pressure in the spectroscopy chamber and $p_{0}$ the equilibrium water vapor pressure (calculated from Eq. 2.5 of Wagner and Pruss[38]) with respect to the sample temperature[26].

For the measurement of the different isobars $(0.05,0.1,0.25$ and 0.5 Torr) the sample was first heated to $\sim 630 \mathrm{~K}$ and spectra of the nominally clean surface were recorded. Subsequently, water vapor was introduced at this elevated sample temperature and then the sample was cooled slowly to as low as $260 \mathrm{~K}$ at constant water vapor pressure (maximum deviation 5\%) while simultaneously recording $\mathrm{O} 1 \mathrm{~s}, \mathrm{C} 1 \mathrm{~s}$ and V 2p XPS spectra (for more details see supporting information). To investigate the desorption of water from the surface the sample was heated after the 0.25 and 0.5 Torr uptake isobars. The experimental results of the four isobar measurements are displayed versus $\mathrm{RH}$ to make them comparable to each 
other. It has to be mentioned here that for the calculation of RH a simplified model was used were sample surface and gas phase are in equilibrium although they might vary in temperature (relevant at high temperature differences between gas and sample). In the supporting information it is explained how to calculate the RH's in a more accurate way (with respect to the different temperature between sample and gas phase), although for our results there is only very small difference between both medoths.

The XPS spectra were analyzed using the commercial software package CasaXPS 2.3.16 PR 1.6. The integrated V 2p and O 1s peak intensities were determined after Shirley background subtraction. For C 1s peaks a linear background was subtracted. All peaks were fitted with Gaussian-Lorentzian (G-L) shapes. As a reference for the peak fitting parameters the works of Biesinger et al.[39] and Siversmit et al.[31] were used. For the V 2p metal peak a G-L mix of 0.62 and an asymmetry of 0.9 was used. The spin-orbit splitting for V $2 p$ was kept constant at $7.62 \mathrm{eV}[40]$. The peak positions, full width at half-maximum (FWHM) and intensities for all peaks were left unconstrained except for the $\mathrm{O} 1 \mathrm{~s}$ peak of the oxygen impurities, which were calculated from the $\mathrm{C}$ 1s signal, and the $\mathrm{O} 1 \mathrm{~s}$ peak of adsorbed water below RH of $\sim 0.01 \%$, where the FWHM was set to $1.67 \mathrm{eV}$ and the position was constrained to $\geq 532.75 \mathrm{eV}$. These values were determined from the peak parameters obtained from unconstrained fits at high $\mathrm{RH}$.

For the calculation of the $\mathrm{O} 1 \mathrm{~s}$ peak intensity due to carbonaceous impurities on the surface the $\mathrm{C} 1 \mathrm{~s}$ peak areas were utilized. According to the compilation of $\mathrm{C} 1 \mathrm{~s}$ binding energies by Briggs and Beamson[41] the binding energy of the adsorbed carbon species is consistent with an acid group ( 288.9 eV). From the integrated C 1s peak area of the acid group-related peak, the corresponding $\mathrm{O} 1 \mathrm{~s}$ peak area was calculated using an experimentally determined $\mathrm{O} / \mathrm{C}$ sensitivity factor from gas phase $\mathrm{CO}_{2}$ measurements using the same spectrometer/beamline settings. The peak area for the O-impurity ( 2 peaks, one each for $\mathrm{C}=\mathrm{O}$ and $\mathrm{C}-\mathrm{OH}$ in the acid group) was set to the corresponding calculated values, with the FWHM held between 1.9 and $2.1 \mathrm{eV}$ and the position constrained to $532.15-532.20 \mathrm{eV}$ and $\geq 533.5$ $\mathrm{eV}$. During the isobar experiments the total amount of carbon impurities remained nearly the same with typical values of $\sim 10 \%$ ML equivalent.

Care was taken to avoid electron or photon induced reactions at the sample surface, especially hydroxylation. This effect has been reported in earlier XPS studies[26, 42]. We have observed that the vanadium-water system is relatively insensitive to beam-induced effects. To investigate the influence of beam exposure we measured the $\mathrm{O} 1 \mathrm{~s}$ and $\mathrm{V} 2 \mathrm{p}$ spectra at two different positions at a given $\mathrm{RH}$. At the first position only a single $\mathrm{O} 1 \mathrm{~s}$ and $\mathrm{V} 2 \mathrm{p}$ scan 
was recorded. The second position was exposed for several minutes to the X-ray beam. Spectra recorded at these two positions showed no significant difference. Nevertheless, to avoid long-term effects of the X-ray beam, fresh measurements spots were chosen after every couple of spectra and the X-ray beam was shut off by a piezo shutter between the single XPS measurements.

For the calculations of the thickness of the $\mathrm{V}_{2} \mathrm{O}_{3}$ layer an overlayer model was used. The calculations were performed using the "XPS Thickness Solver" programmed by Smith et al.[43]. The input parameters for the program are the photoemission angle (48 deg, between surface normal and analyzer), the inelastic mean free paths (see table 1, supporting information), the peak intensities of substrate and overlayer, the relative sensitivity factor (in this equation set to 1 because the calculations are for the same element: $\mathrm{V}$ and $\mathrm{V}_{2} \mathrm{O}_{3}$ ), and the atomic density for $\mathrm{V}$ in the metal $\left(7.22 \times 10^{22}\right.$ atoms $\left./ \mathrm{cm}^{3}\right)$ and in $\mathrm{V}_{2} \mathrm{O}_{3}\left(1.96 \times 10^{22}\right.$ atoms $\left./ \mathrm{cm}^{3}\right)$.

For the calculations of the IMFP the NIST Database \#82 was used[44]. The input parameters for $\mathrm{V}$ are the electron kinetic energy, the optical band gap $(0.6 \mathrm{eV})[45]$ and the asymmetry parameters (for values see table 1, supporting information). Asymmetry parameters were obtained from the Elettra Trieste Synchrotron database[46]. The calculation was performed using the TTP $2 \mathrm{M}$ equation. For $\mathrm{V}_{2} \mathrm{O}_{3}$ the stoichiometry and the valence electrons per molecule (28) were used.

\section{Results and Discussion}

First we present XPS data from an isothermal reaction of the cleaned vanadium foil with water vapor at $310 \mathrm{~K}$. Fig. 1a shows the V $2 \mathrm{p}_{1 / 2}$ and $\mathrm{V} 2 \mathrm{p}_{3 / 2}$ spectra at $2.5 \times 10^{-9}$ Torr of $\mathrm{H}_{2} \mathrm{O}$. At this pressure the spectrum shows mainly the metallic vanadium peak at $\sim 512.2 \mathrm{eV}$ binding energy. Small traces of $\mathrm{VO}_{\mathrm{x}}$ can be seen above $515.2 \mathrm{eV}$. These are due to remaining O-impurities. Increasing the $\mathrm{H}_{2} \mathrm{O}$ pressure to $2.5 \times 10^{-8}$ and then to $2.5 \times 10^{-7}$ Torr does not bring any changes to the V $2 \mathrm{p}$ spectra (not shown). At $1.2 \times 10^{-6}$ Torr $\mathrm{H}_{2} \mathrm{O}$ first changes in the $\mathrm{V} 2 \mathrm{p}$ spectra appear (Fig. 1b). The peak broadens because of the appearance of vanadium hydroxide (V-OH, $\sim 513 \mathrm{eV})[31]$ and the vanadium oxide component ( 515.5 eV)[47], indicating the beginning of surface hydroxylation and oxidation by water vapor. At $1.2 \times 10^{-5}$ Torr $\mathrm{H}_{2} \mathrm{O}$ (Fig. 1c) a significant rise in the vanadium oxide component can be seen. These results show that at $310 \mathrm{~K}$ surface hydroxylation commences between $10^{-6}$ and $10^{-5}$ Torr $\mathrm{H}_{2} \mathrm{O}$, concomitant with the formation of a surface oxide layer on the vanadium foil. Further increase in water vapor pressure leads to a continuous growth of the vanadium oxide signal. 


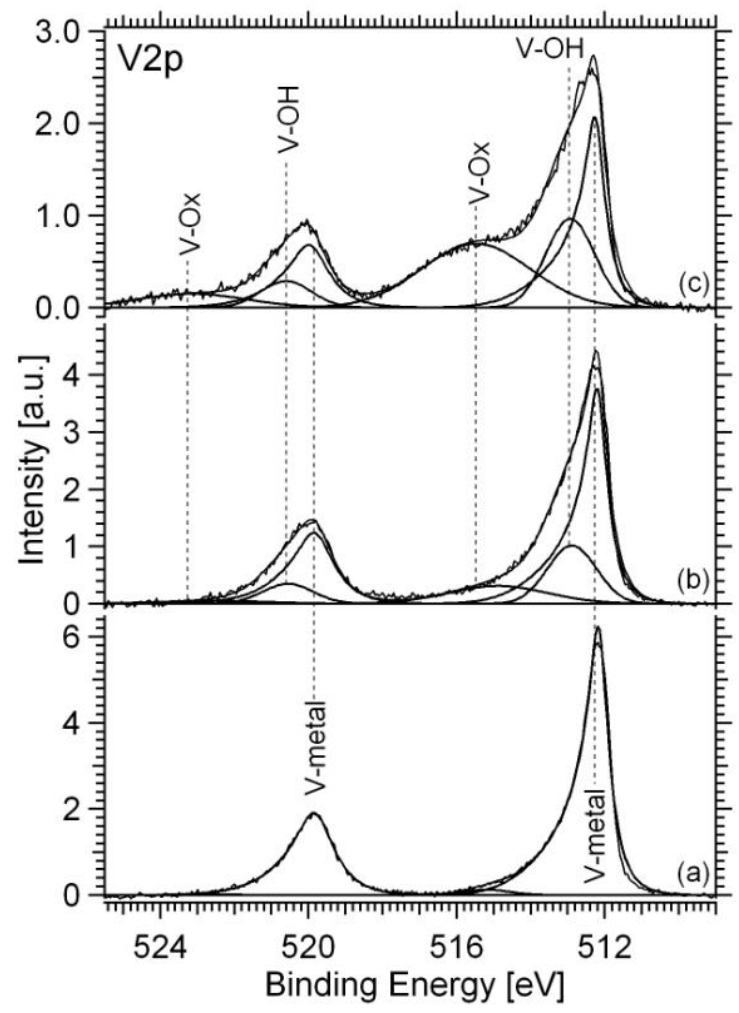

Fig. 1. $V 2 p_{1 / 2}$ and $V 2 p_{3 / 2}$ AP-XPS spectra of $V$-foil at $310 \mathrm{~K}$ in water vapor. The water pressure is (a) $2.5 \times 10^{-9}$ Torr, (b) $1.2 \times 10^{-6}$ Torr and (c) $1.2 \times 10^{-5}$ Torr. At $310 \mathrm{~K}$ the surface oxidation and hydroxylation starts at a pressure of $1 \times 10^{-6}$ Torr of $\mathrm{H}_{2} \mathrm{O}$.

Fig. 2 illustrates the changes in the V $2 p$ spectra during the isobaric reaction in 0.005 Torr $\mathrm{H}_{2} \mathrm{O}$. Fig. 2a shows the V 2p signal in UHV at $670 \mathrm{~K}$ prior to dosing water vapor. The spectrum is similar to that for $2.5 \times 10^{-9}$ Torr $\mathrm{H}_{2} \mathrm{O}$ in Fig. 1a, showing the V-metal peak (BE $512.2 \mathrm{eV}$ ) and traces of $\mathrm{VO}_{\mathrm{x}}$. After exposing the vanadium foil to 0.005 Torr $\mathrm{H}_{2} \mathrm{O}$ at $530 \mathrm{~K}$ (Fig. $2 \mathrm{~b}, \mathrm{RH}=1.59 \times 10^{-5} \%$ ) the V $2 \mathrm{p}$ spectrum shows peaks due to V-oxide (V-Ox, BE $515.3 \mathrm{eV})$ and $\mathrm{V}-\mathrm{OH}(\mathrm{BE} 513.2 \mathrm{eV})$. With increasing $\mathrm{RH}$ up to $0.052 \%(\mathrm{~T}=285 \mathrm{~K})$ the oxide signal is increasing relative to the metal peak (Fig. 2c). The oxide peak position ( $\mathrm{BE}=$ $515.3 \mathrm{eV})$ and the broad FWHM (>3.5 eV) indicate that the oxide layer is $\mathrm{V}_{2} \mathrm{O}_{3}[31,33]$. The analysis of depth profile measurements yields a thickness of the $\mathrm{V}_{2} \mathrm{O}_{3}$ layer of $\sim 1.2 \mathrm{~nm}$. Literature values for the thickness of a $\mathrm{V}_{2} \mathrm{O}_{3}$ monolayer vary depending on the substrate on which the vanadium oxide growths and on the total thickness of the oxide (bulk vs. thin film)[33, 48]. The vanadium foil in the present case is polycrystalline with many different surface orientations. With an assumed thickness of a $\mathrm{V}_{2} \mathrm{O}_{3}$ monolayer of $0.3 \mathrm{~nm}$ the thickness of the oxide layer at RH $0.05 \%$ is thus $\sim 4 \mathrm{ML}$ (see also supporting information). 


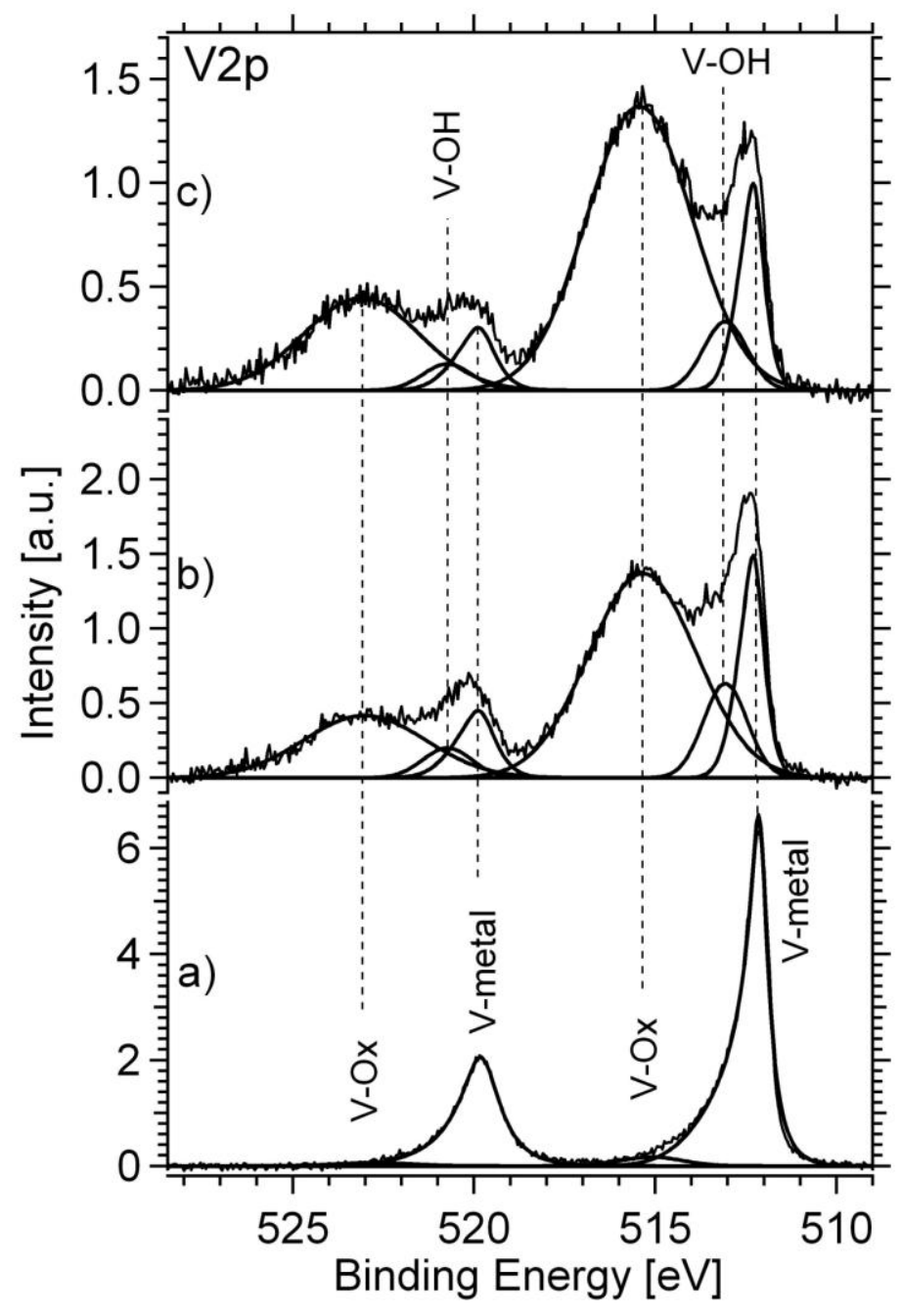

Fig. 2. $V 2 p_{1 / 2}$ and $V 2 p_{3 / 2}$ AP-XPS spectra of a) clean $V$-foil at $670 \mathrm{~K}$ in $\left.U H V, b\right) V$-foil in 0.005 Torr of $\mathrm{H}_{2} \mathrm{O} @ 530 \mathrm{~K}\left(\mathrm{RH}=1.59 \times 10^{-5} \%\right)$, c) V-foil in 0.005 Torr of $\mathrm{H}_{2} \mathrm{O}$ at $285 \mathrm{~K}(\mathrm{RH}$ $=0.052 \%)$. The spectral intensities are normalized to the background

Fig. 3 shows the V 2p spectra for a depth profile at a water vapor pressure of 0.5 Torr and a sample temperature of $267 \mathrm{~K}(\mathrm{RH}=16.7 \%)$. The spectra are normalized to the maximum V-metal peak intensity for better illustration of the changes in the ratio between $\mathrm{V}$ metal and V-oxide. With increasing analysis depth the $\mathrm{V}$-oxide peak at $515.3 \mathrm{eV}$ is decreasing in intensity relative to the $\mathrm{V}$-metal signal at $512.2 \mathrm{eV}$. The data clearly shows that the $\mathrm{V}_{2} \mathrm{O}_{3}$ oxide layer is on the surface of the vanadium foil. Thickness calculations from the peak areas of the V $2 p$ depth profiles give a thickness of $\sim 1.4 \mathrm{~nm}(\sim 4 \mathrm{ML})$ for the $\mathrm{V}_{2} \mathrm{O}_{3}$ layer under these conditions. 


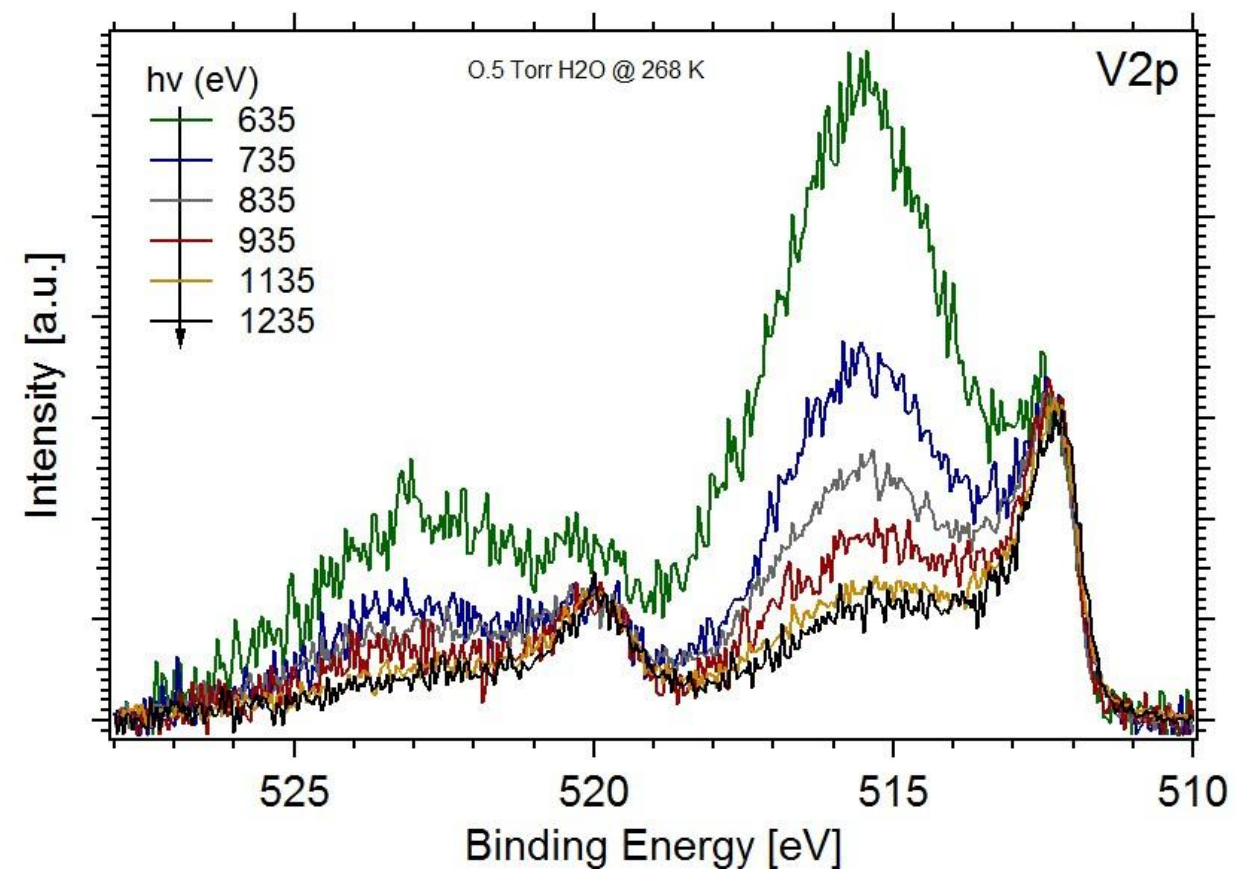

Fig. 3. AP-XPS depth profile for $V 2 p$ spectra. By varying the incident photon energy the probing depth can be varied. The incident photon energy was $635 \mathrm{eV}, 735 \mathrm{eV}, 835 \mathrm{eV}, 935$ $\mathrm{eV}, 1135 \mathrm{eV}$ and $1235 \mathrm{eV}$ corresponding to a kinetic energy of the photoelectrons of $\sim 120 \mathrm{eV}$, $220 \mathrm{eV}, 320 \mathrm{eV}, 420 \mathrm{eV}, 520 \mathrm{eV}$ and $620 \mathrm{eV}$. The spectra are normalized to the V-metal peak (BE $512.2 \mathrm{eV}$ ). With increasing probing depth clearly the decrease of the $V$-oxide signal (BE $515.3 \mathrm{eV}$ ) can be seen.

We now turn our attention to the analysis of the $\mathrm{O} 1 \mathrm{~s}$ spectra, which provide information on the thickness of the adsorbed water and hydroxyl layers. The calculations for the thickness of the V-OH and $\mathrm{H}_{2} \mathrm{O}$ layers are described in detail in Ref. [24]. Fig. 4 shows the components of the $\mathrm{O} 1 \mathrm{~s}$ spectra. The spectrum in the upper panel was taken at $590 \mathrm{~K}$ and 0.01 Torr of water $\left(\mathrm{RH}=1.3 \times 10^{-5} \%\right)$, while the lower spectrum was measured at $270 \mathrm{~K}$ and 0.25 Torr $(\mathrm{RH}=6.9 \%)$. Two peaks are observed in the spectrum at lower $\mathrm{RH}, \mathrm{V}_{2} \mathrm{O}_{3}$ at $530.15 \mathrm{eV}$ and $\mathrm{V}-\mathrm{OH}$ at $530.95 \mathrm{eV}[31,49]$. At the higher RH additional peaks for adsorbed water at $532.8 \mathrm{eV}, \mathrm{COOH}$-impurities at $532.1 \mathrm{eV} / 533.5 \mathrm{eV}$ and water gas phase at $534.7 \mathrm{eV}$ are detected. Representative $\mathrm{C} 1 \mathrm{~s}$ spectra, which are used to determine the corresponding $\mathrm{O} 1 \mathrm{~s}$ peak areas of the COOH-impurities, are shown in Fig. 5. A detailed assignment and calculation of peaks and peak areas was already discussed in the experimental section. The binding energy of the adsorbed water $(\sim 533 \mathrm{eV})$ is similar to the results on $\mathrm{Cu}(110)$ and $\mathrm{Cu}_{2} \mathrm{O}[27,50]$. The position of the gas phase water peak strongly depends on the work function of the sample and can therefore change during an experiment[51]. In our work the 
apparent gas phase water $\mathrm{BE}$ varies between $533.6 \mathrm{eV}$ and $535.8 \mathrm{eV}$. For water adsorption studies on $\mathrm{MgO}$ and $\mathrm{Cu}$ shifts between $\sim 535-536 \mathrm{eV}$ were observed[26, 52].

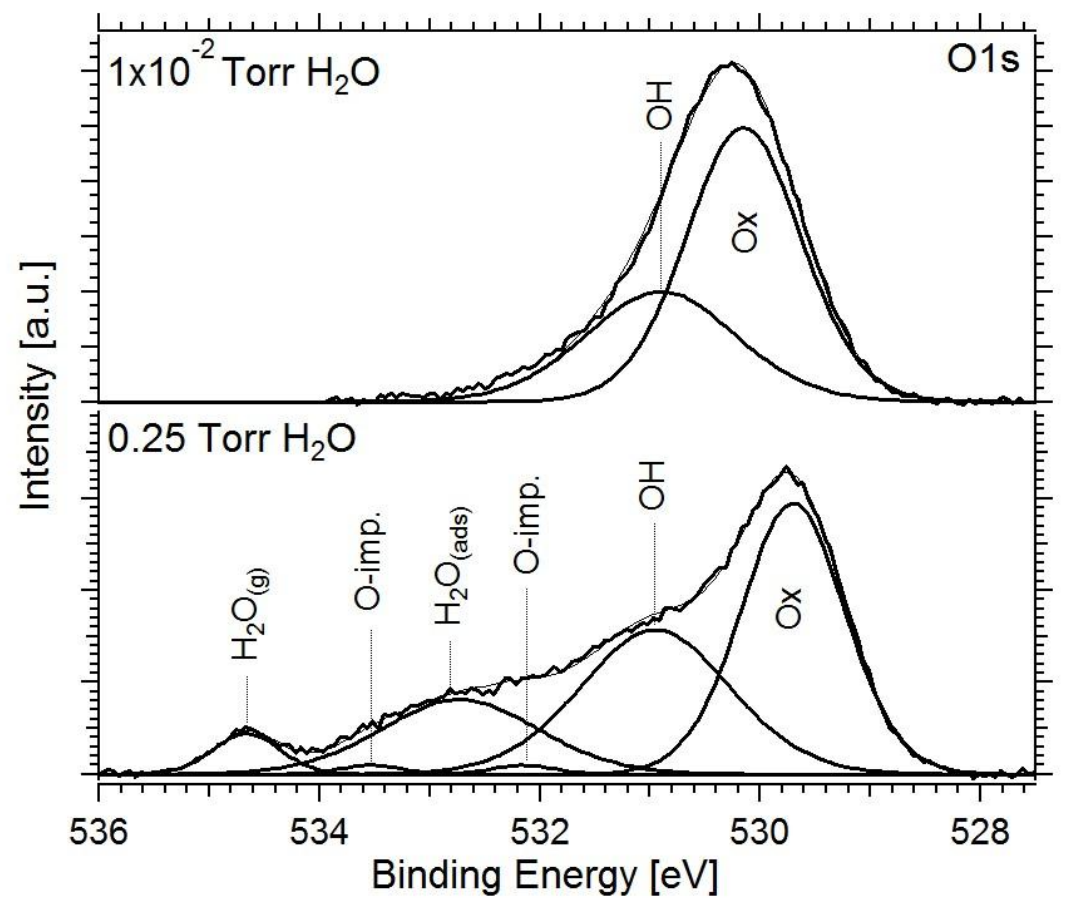

Fig. 4. $O$ 1s AP-XPS spectra of a $V$-foil. Upper panel shows the $V$-foil at $590 \mathrm{~K}$ in $1 \times 10^{-2}$ Torr of $\mathrm{H}_{2} \mathrm{O}\left(\mathrm{RH}=1.3 \times 10^{-5} \%\right)$. The oxide peak $(\mathrm{Ox})$ corresponds to the $\mathrm{V}_{2} \mathrm{O}_{3}$ and the $\mathrm{OH}$ peak to $\mathrm{V}$-OH. Lower panel: $\mathrm{V}$-foil in 0.25 Torr $\mathrm{H}_{2} \mathrm{O}$ at $270 \mathrm{~K}(\mathrm{RH}=6.87 \%)$. The additional peaks correspond to the gas phase water $\left(H 2 \mathrm{O}_{(\mathrm{g})}\right)$, the adsorbed water on the $\mathrm{V}$-foil $\left(\mathrm{H} 2 \mathrm{O}_{(\mathrm{ads})}\right)$ and the O-impurities (O-imp) due to carbon impurities on the surface. 


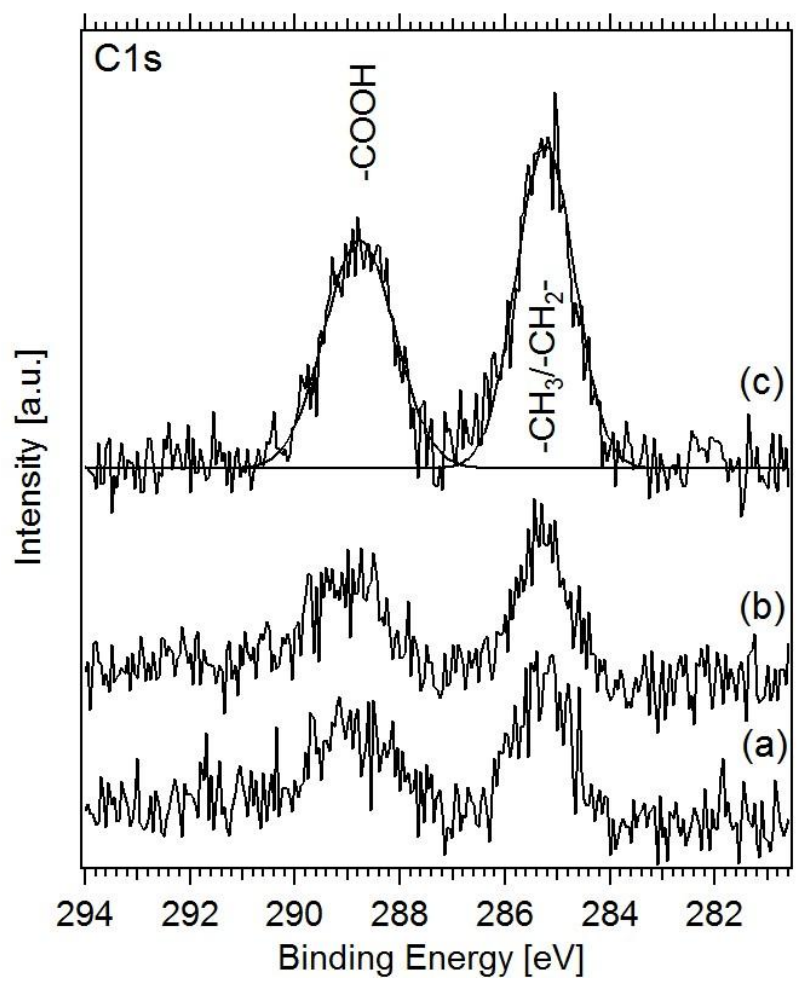

Fig. 5. C1s AP-XPS spectra of carbon impurities on a $\mathrm{V}$-foil. (a) 0.05 Torr $\mathrm{H}_{2} \mathrm{O}$ at $505 \mathrm{~K}(\mathrm{RH}$ $\left.=2.3 \times 10^{-4} \%\right)$, (b) 0.05 Torr $\mathrm{H}_{2} \mathrm{O}$ at $360 \mathrm{~K}\left(\mathrm{RH}=1.2 \times 10^{-2} \%\right)$, (c) $0.05 \mathrm{Torr} \mathrm{H}_{2} \mathrm{O}$ at $262 \mathrm{~K}$ $(\mathrm{RH}=2.5 \%)$. The two species are aliphatic $\left(-\mathrm{CH}_{x}\right)$ and acidic carbon $(-\mathrm{COOH})$.

Fig. 6 shows the $\mathrm{O}$ 1s spectra for an isobar experiment at 0.1 Torr water vapor pressure. The sample was cooled from $520 \mathrm{~K}$ to $275 \mathrm{~K}$. In this figure only a selection of the collected $\mathrm{O} 1 \mathrm{~s}$ spectra is shown for clarity, but the calculations of the peak areas for the uptake data shown in Fig. 7 were done on all spectra. With increasing RH a shoulder near $533.2 \mathrm{eV}$ is growing, indicating the adsorption of water molecules on the surface. The ratio between $\mathrm{V}-\mathrm{OH}$ and $\mathrm{V}_{2} \mathrm{O}_{3}$ stays nearly constant throughout the isobar experiment. 


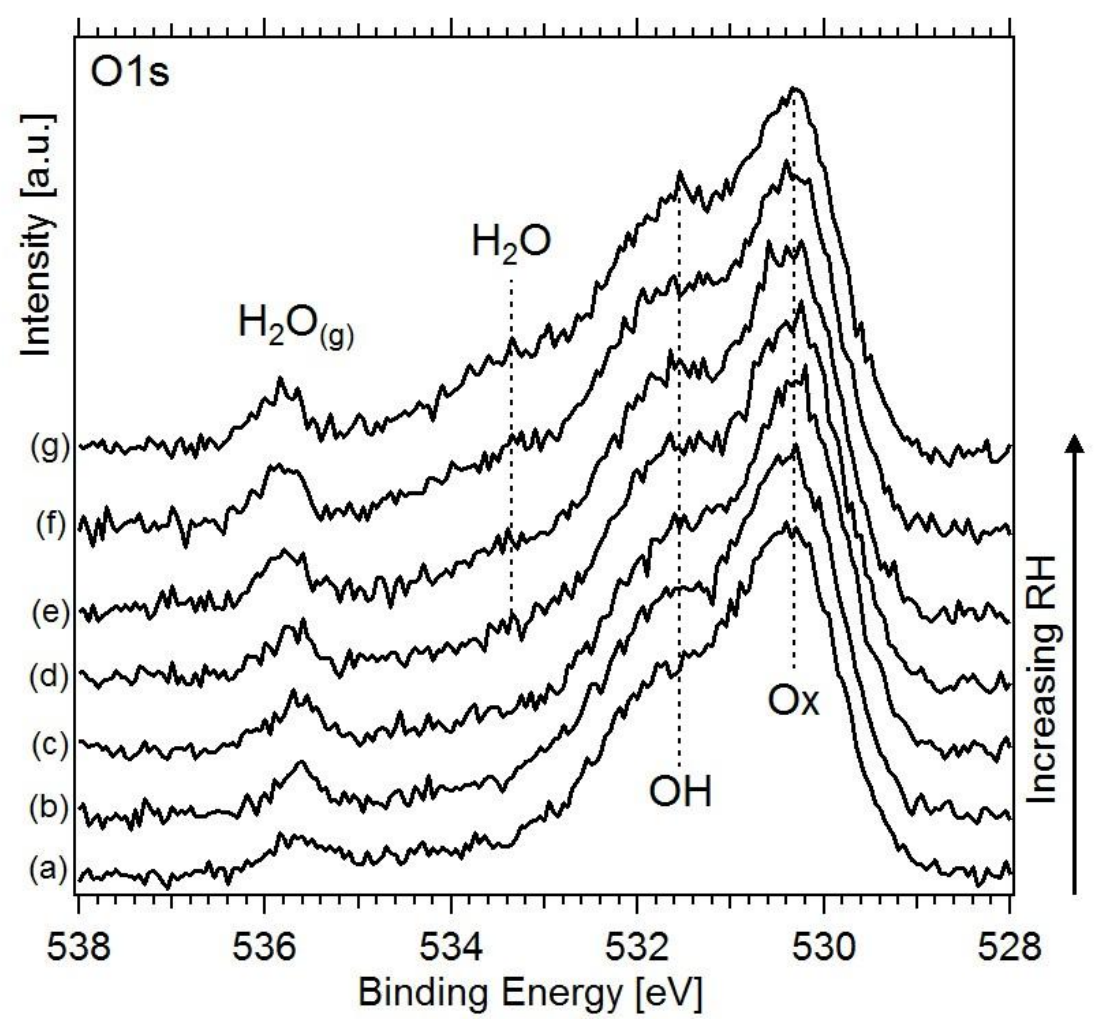

Fig. 6. $O$ 1s AP-XPS spectra of a 0.1 Torr water vapor isobar on a $V$-foil. The sample was cooled from $520 \mathrm{~K}$ to $275 \mathrm{~K}$, with corresponding $\mathrm{RH}$ values of (a) $7.3 \times 10^{-4} \%$, (b) $2.5 \times 10^{-3}$ $\%$, (c) $1.0 \times 10^{-2} \%$, (d) $9.3 \times 10^{-2} \%$, (e) $0.29 \%$, (f) $0.84 \%$, and (g) $1.6 \%$. Spectral intensities were normalized to the background.

Fig. 7 presents the results from four different water uptake isobar measurements at 0.05 Torr, 0.1 Torr, 0.25 Torr and 0.5 Torr of water vapor (full circles). Between the isobar experiments the vanadium foil was cleaned by several sputter and anneal cycles. While cooling down the sample in water vapor, O 1s spectra and - less frequently - C 1s and V $2 p$ spectra were recorded throughout the isobar experiments. With this procedure it is possible to record an $\mathrm{O}$ 1s spectrum every few Kelvin. After peak fitting of the $\mathrm{O} 1 \mathrm{~s}$ spectra the areas of the oxide, $\mathrm{OH}$ and $\mathrm{H}_{2} \mathrm{O}$ components were determined and then used to calculate the various film thicknesses. In addition to the uptake experiments (increasing $\mathrm{RH}$ ) for the 0.5 Torr and 0.25 Torr isobars, desorption experiments were performed (open triangles). In those experiments the sample was heated to higher temperatures up to $500 \mathrm{~K}$ while simultaneous monitoring the $\mathrm{O} 1 \mathrm{~s}, \mathrm{~V} 2 \mathrm{p}$ and $\mathrm{C} 1 \mathrm{~s}$ core level. The data in Fig. 7 (green and blue open triangles) show that the process is fully reversible for adsorbed water, vanadium hydroxide and oxide. Only for the 0.25 Torr isobar a small deviation can be seen at very low relative humidity. 


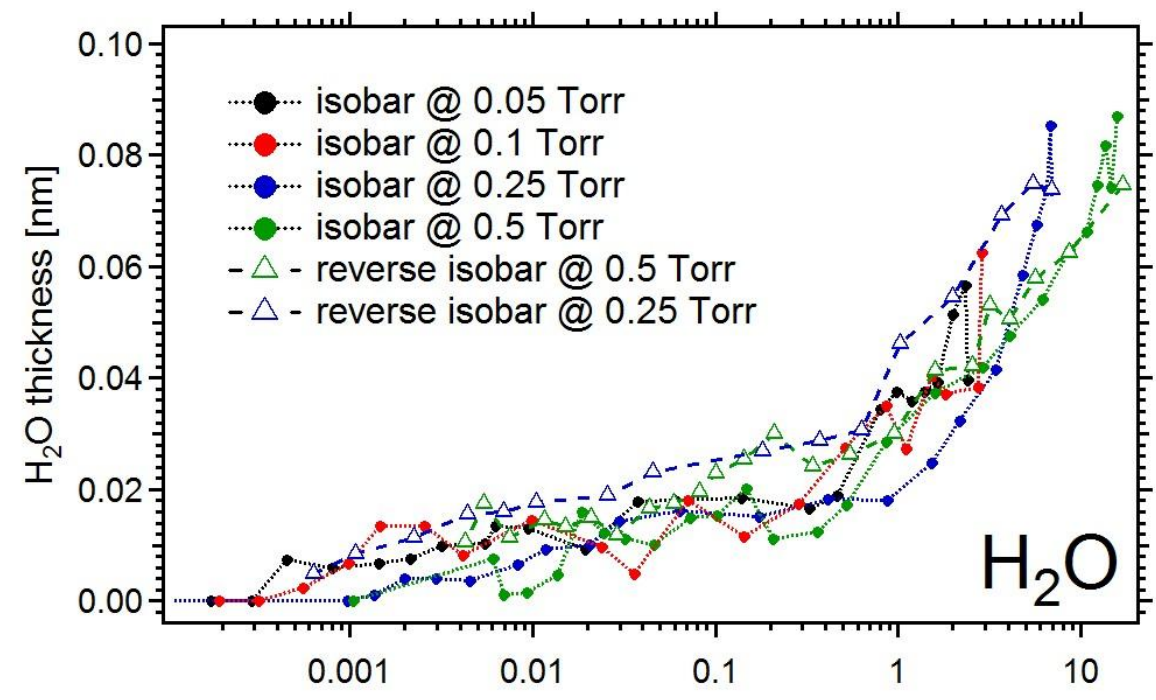

Relative Humidity [\%]

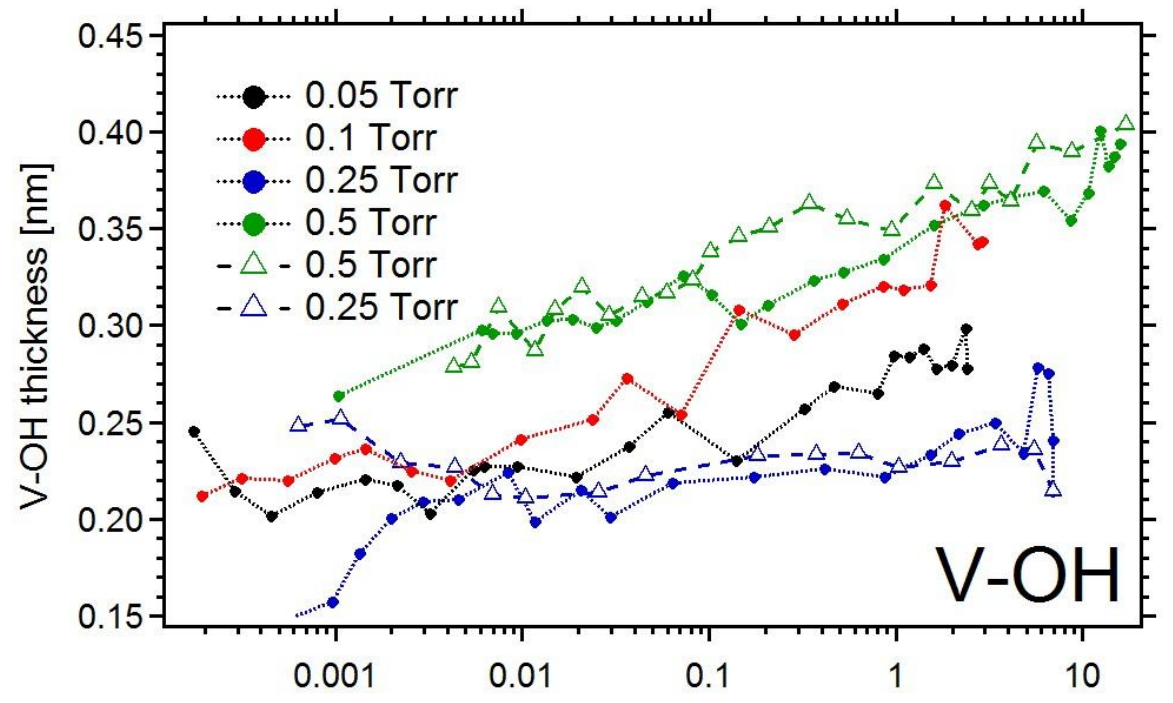

Relative Humidity [\%]

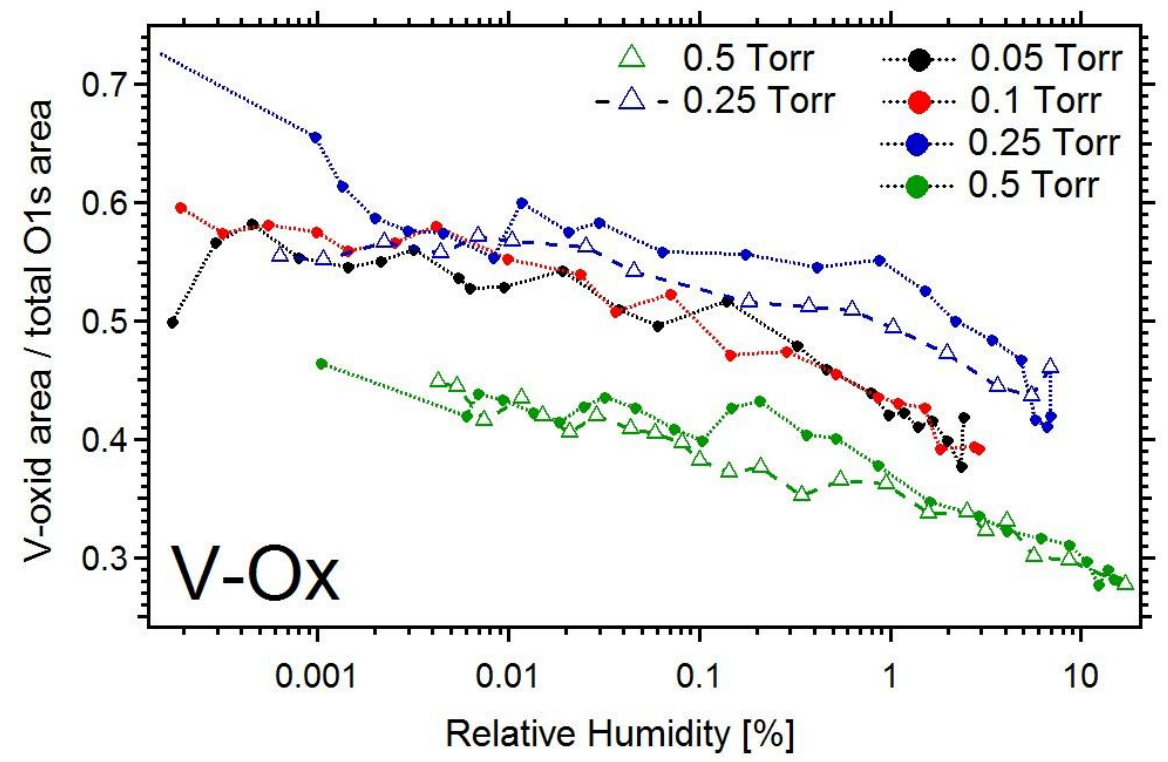


Fig. 7. Isobar curves for 0.5 (green), 0.25 (blue), 0.1 (red) and 0.05 (black) Torr water vapor pressure. The top panel shows the curves for molecular adsorbed water, the middle panel for $\mathrm{V}$-OH and the lower panel for the V-Ox component of the Ols spectra. The data was collected in situ using AP-XPS (O1s signal, $735 \mathrm{eV}$ photon energy). Lines with circles are isobar measurements with decreasing temperature and lines with open triangles are the corresponding reverse experiments by heating up under isobar conditions.

For the calculations of the film thicknesses a multilayer film XPS model described in detail in Ref. [24] was used. The multilayer model used in this study has some limitations for the coverage calibration of $\mathrm{OH}$ and $\mathrm{H}_{2} \mathrm{O}$. This model assumes uniform layers of $\mathrm{OH}$ and $\mathrm{H}_{2} \mathrm{O}$, but the adsorbed water layer could also grow as three-dimensional islands. Studies for water adsorption by Toledano et al. on $\mathrm{V}_{2} \mathrm{O}_{3}$ under UHV conditions did not indicate threedimensional island growth, however[53]. But a detailed discussion about the layer growth of adsorbed water on $\mathrm{V}_{2} \mathrm{O}_{3}$ at ambient conditions would require additional measurements by microscopic methods with high spatial resolution, such as scanning probe microscopy as shown by Missert et al. on $\mathrm{Al}_{2} \mathrm{O}_{3}[54]$.

The lower panel of Fig. 7 shows the results for the vanadium oxide, where the amount of oxide is shown as oxide divided by the total peak area of all O1s peaks. For all four isobars a decrease of the oxygen area with increasing RH is observed, with the initial oxide thickness also slightly depending on the sample temperature at the point where the water was dosed into the measurement chamber. For example for the 0.25 Torr isobar the water was dosed at $585 \mathrm{~K}$ and for the 0.05 Torr isobar it was dosed at $515 \mathrm{~K}$. The 0.25 Torr isobar has a slightly higher content of oxide than the one at 0.05 Torr as can be seen in the Fig. 7. To determine the exact growth mechanism of $\mathrm{V}$-oxide and $\mathrm{V}-\mathrm{OH}$ would require a dedicated study, as it is shown for example by Surnev et al. for the case of vanadium oxide growth on $\operatorname{Pd}(111)$ investigated by STM[33].

With increasing $\mathrm{RH}$ the oxide thickness is shrinking due to the decreasing fraction of oxide in the probed surface layer through addition of $\mathrm{OH}$ and $\mathrm{H}_{2} \mathrm{O}$, as well as due to the increased attenuation of photoelectrons originating from the oxide by the growth of $\mathrm{OH}$ and $\mathrm{H}_{2} \mathrm{O}$ layers. In addition, a small part of the oxide layer is converted to $\mathrm{V}-\mathrm{OH}$ at higher relative humidity. Water adsorption studies on $\mathrm{MgO}$ show a similar behavior[26]. This process is dynamic and can be reversed by decreasing the relative humidity (green and blue open triangles). The oxide thickness calculated from the V $2 p$ depth profiles is between $\sim 3$ and $\sim 5$ ML for the four isobars. 
The middle panel in Fig. 7 shows the V-OH thickness for the different isobars. With increasing $\mathrm{RH}$ the thickness of the $\mathrm{V}-\mathrm{OH}$ layer is increasing slightly by conversion of $\mathrm{V}$-oxide to $\mathrm{V}-\mathrm{OH}$ as described earlier. The initial V-OH layers are grown simultaneously to $\mathrm{V}$-oxide at very low water pressures $\left(1 \times 10^{-6}\right.$ Torr $)$ during the initial exposure of the sample to water vapor. Previous studies of water adsorption on different surfaces show that for $\alpha-\mathrm{Fe}_{2} \mathrm{O}_{3}(0001)$, $\mathrm{Fe}_{3} \mathrm{O}_{4}(001)$, and $\mathrm{TiO}_{2}$ an immediate surface hydroxylation appears at very low water vapor pressures[24, 52]. The amount of hydroxide is almost constant with increasing RH until terrace hydroxylation (in the case of the iron oxides) sets in at RH $0.01 \%$. In the present case the $\mathrm{V}-\mathrm{OH}$ is growing with increasing $\mathrm{RH}$ which is similar to the $\mathrm{Cu}$ case[50]. Research (Scanned-energy mode photoelectron diffraction) and DFT calculations of the local structure of $\mathrm{OH}$ species on $\mathrm{V}_{2} \mathrm{O}_{3}$ by Kröger et al.[55] describe a structure model of the surface with a possible maximum coverage of up to $4 \mathrm{ML}$ of $\mathrm{V}-\mathrm{OH}$ (vanadyl oxygen and three-fold oxygen site are $\mathrm{OH}$-terminated). But their experimental data did not show that high coverages in their UHV studies. The thickness of $\mathrm{V}-\mathrm{OH}$ in our water adsorption study is initially $\sim 1 \mathrm{ML}$ and increases up to $~ 1.5 \mathrm{ML}$ at the highest $\mathrm{RH}$ of $15 \%$.

The upper panel of Fig. 7 shows the uptake data for the adsorbed water. The results of the four different isobars are consistent. Above a RH of $\sim 0.001 \%$ the adsorption of molecular water is observed. From RH $0.001 \%$ up to $\mathrm{RH} \sim 0.5 \%$ the amount of adsorbed water is increasing very slowly and above RH $0.5 \%$ a steeper increase of adsorbed water can be seen. Due to the experimental limitations it was not possible to achieve RHs higher than $\sim 16 \%$. The total amount of adsorbed water is very low, in the sub monolayer regime with a maximum of $\sim 1 / 3$ ML coverage above a RH of 10\%[17]. Investigations for water adsorption on $\mathrm{V}_{2} \mathrm{O}_{3}$ by $\mathrm{Abu}$ Haija et al.[49] using XPS and Infrared Spectroscopy (temperature range 88 $\mathrm{K}-723 \mathrm{~K}$ ) show that the amount of adsorbed water strongly depends on the surface termination of the $\mathrm{V}_{2} \mathrm{O}_{3}$. For vanadyl terminated surfaces a coverage of $\sim 0.5-1.1$ water molecules per unit cell was observed, while the vanadium-terminated surfaces showed a coverage of $\sim 2.3$ in their UHV studies. Abu Haija et al. also show that water fully desorbs from the surface above $300 \mathrm{~K}$ in UHV. In our desorption experiments in the presence of 0.25 Torr or 0.5 Torr water vapor, adsorbed water is present up to the highest temperature $(500 \mathrm{~K})$. This clearly shows the difference of UHV and low temperature studies and experiments for surfaces at elevated pressures.

\section{Conclusions}


We have investigated the interaction of a polycrystalline vanadium metal surface with water vapor under isothermal and isobaric conditions using ambient pressure XPS. In this study the vanadium foil is easily hydroxylated and oxidized by dissociatively adsorbed water already at relative humidities as low as $4 \times 10^{-6} \%\left(1 \times 10^{-6}\right.$ Torr at $\left.310 \mathrm{~K}\right)$. With increasing water vapor pressure a thin $\mathrm{V}$-oxide film $\left(\mathrm{V}_{2} \mathrm{O}_{3}\right)$ and a $\mathrm{V}$-OH layer is formed. Depth profile measurements reveal a thickness of the oxide layer of $~ 3-5 \mathrm{ML}$ for the different isobars. The thickness of the $\mathrm{V}-\mathrm{OH}$ layer increases slightly with increasing $\mathrm{RH}$ from $\sim 1 \mathrm{ML}$ up to a maximum of $\sim 1.5 \mathrm{ML}$. The formation of the $\mathrm{V}-\mathrm{OH}$ layer is a dynamic process and the thickness of the $\mathrm{V}-\mathrm{OH}$ layer depends on the $\mathrm{RH}$. The isobar experiments at 0.05 Torr, 0.1 Torr, 0.25 Torr and 0.5 Torr show that molecular water adsorption starts at a RH of $\sim 0.001 \%$. Up to a RH of $0.5 \%$ a slow increase of adsorbed water can be observed. Above $0.5 \% \mathrm{RH}$ a fast growth in the water adsorption layer can be seen. The coverage with adsorbed water is very low, in the sub-monolayer range for the highest RHs in this study ( 15\%). In desorption experiments it was shown that the molecular water adsorption process is reversible.

\section{Acknowledgement}

The ALS and the MES beamline 11.0.2 are supported by the Director, Office of Science, Office of Basic Energy Sciences, and by the Division of Chemical Sciences, Geosciences, and Biosciences of the US Department of Energy at the Lawrence Berkeley National Laboratory under Contract No. DE-AC02-05CH11231. Christoph Rameshan acknowledges support by the Austrian Science Fund (FWF) via an Erwin-Schrödinger Scholarship [J3208 N-19]. May Ling Ng gratefully acknowledges the postdoctoral fellowship from Wenner-Gren Foundations in Stockholm, Sweden. John T. Newberg acknowledges support from an NSF postdoctoral fellowship (ANT-1019347).

\section{Appendix A. Supplementary data}

\section{References}

[1] D.A. King, D.P. Woodruff, Fundamental studies of heterogeneous catalysis, Elsevier Scientific Publishing Co., 1982.

[2] I. Chorkendorff, J.W. Niemantsverdriet, Concepts of modern catalysis and kinetics, Wiley-VCH, 2003.

[3] A. Nilsson, L.G.M. Pettersson, J. Norskov, Chemical Bonding at Surfaces and Interfaces, Elsevier Science, 2007. 
[4] M.A. Zondlo, P.K. Hudson, A.J. Prenni, M.A. Tolbert, Annual Review of Physical Chemistry. 51 (2000) 473-+.

[5] C. Girardet, C. Toubin, Surface Science Reports. 44 (2001) 163-238.

[6] G.E. Brown, V.E. Henrich, W.H. Casey, D.L. Clark, C. Eggleston, A. Felmy, D.W. Goodman, M. Gratzel, G. Maciel, M.I. McCarthy, K.H. Nealson, D.A. Sverjensky, M.F. Toney, J.M. Zachara, Chemical Reviews. 99 (1999) 77-174.

[7] C. Leygraf, T.E. Graedel, Atmospheric corrosion, Wiley-Interscience, 2000.

[8] M.J. Weaver, X.P. Gao, Annual Review of Physical Chemistry. 44 (1993) 459-494.

[9] N.M. Markovic, P.N. Ross, Surface Science Reports. 45 (2002) 121-229.

[10] S. Krishnamoorthy, M. Tu, M.P. Ojeda, D. Pinna, E. Iglesia, Journal of Catalysis. 211 (2002) 422-433.

[11] A. Bongiorno, U. Landman, Physical Review Letters. 95 (2005).

[12] J. Bergeld, B. Kasemo, D.V. Chakarov, Surface Science. 495 (2001) L815-L820.

[13] M. Date, M. Haruta, Journal of Catalysis. 201 (2001) 221-224.

[14] J. Saavedra, H.A. Doan, C.J. Pursell, L.C. Grabow, B.D. Chandler, Science. 345 (2014) 1599-1602.

[15] G. Ketteler, S. Yamamoto, H. Bluhm, K. Andersson, D.E. Starr, D.F. Ogletree, H. Ogasawara, A. Nilsson, M. Salmeron, Journal of Physical Chemistry C. 111 (2007) 8278-8282.

[16] S.G. Moussa, T.M. McIntire, M. Szori, M. Roeselova, D.J. Tobias, R.L. Grimm, J.C. Hemminger, B.J. Finlayson-Pitts, Journal of Physical Chemistry A. 113 (2009) 20602069.

[17] G.E. Ewing, Chemical Reviews. 106 (2006) 1511-1526.

[18] P.A. Thiel, T.E. Madey, Surface Science Reports. 7 (1987) 211-385.

[19] M.A. Henderson, Surface Science Reports. 46 (2002) 5-308.

[20] A. Verdaguer, G.M. Sacha, H. Bluhm, M. Salmeron, Chemical Reviews. 106 (2006) 1478-1510.

[21] H. Bluhm, K. Andersson, T. Araki, K. Benzerara, G.E. Brown, J.J. Dynes, S. Ghosal, M.K. Gilles, H.C. Hansen, J.C. Hemminger, A.P. Hitchcock, G. Ketteler, A.L.D. Kilcoyne, E. Kneedler, J.R. Lawrence, G.G. Leppard, J. Majzlan, B.S. Mun, S.C.B. Myneni, A. Nilsson, H. Ogasawara, D.F. Ogletree, K. Pecher, M. Salmeron, D.K. Shuh, B. Tonner, T. Tyliszczak, T. Warwick, T.H. Yoon, Journal of Electron Spectroscopy and Related Phenomena. 150 (2006) 86-104. 
[22] A. Nilsson, Journal of Electron Spectroscopy and Related Phenomena. 126 (2002) 342.

[23] S. Yamamoto, K. Andersson, H. Bluhm, G. Ketteler, D.E. Starr, T. Schiros, H. Ogasawara, L.G.M. Pettersson, M. Salmeron, A. Nilsson, Journal of Physical Chemistry C. 111 (2007) 7848-7850.

[24] S. Yamamoto, T. Kendelewicz, J.T. Newberg, G. Ketteler, D.E. Starr, E.R. Mysak, K.J. Andersson, H. Ogasawara, H. Bluhm, M. Salmeron, G.E. Brown, Jr., A. Nilsson, Journal of Physical Chemistry C. 114 (2010).

[25] T. Kendelewicz, S. Kaya, J.T. Newberg, H. Bluhm, N. Mulakaluri, W. Moritz, M. Scheffler, A. Nilsson, R. Pentcheva, G.E. Brown, Jr., Journal of Physical Chemistry C. 117 (2013) 2719-2733.

[26] J.T. Newberg, D.E. Starr, S. Yamamoto, S. Kaya, T. Kendelewicz, E.R. Mysak, S. Porsgaard, M.B. Salmeron, G.E. Brown, Jr., A. Nisson, H. Bluhm, Journal of Physical Chemistry C. 115 (2011).

[27] X. Deng, T. Herranz, C. Weis, H. Bluhm, M. Salmeron, Journal of Physical Chemistry C. 112 (2008) 9668-9672.

[28] A. Verdaguer, C. Weis, G. Oncins, G. Ketteler, H. Bluhm, M. Salmeron, Langmuir. 23 (2007) 9699-9703.

[29] S.J. Zinkle, H. Matsui, D.L. Smith, A.F. Rowcliffe, E. van Osch, K. Abe, V.A. Kazakov, Journal of Nuclear Materials. 258 (1998) 205-214.

[30] N.W. Ockwig, T.M. Nenoff, Chemical Reviews. 107 (2007) 4078-4110.

[31] G. Silversmit, D. Depla, H. Poelman, G.B. Marin, R. De Gryse, Journal of Electron Spectroscopy and Related Phenomena. 135 (2004).

[32] I.E. Wachs, Dalton Transactions. 42 (2013) 11762-11769.

[33] S. Surnev, M.G. Ramsey, F.P. Netzer, Progress in Surface Science. 73 (2003) 117 165.

[34] T.D. Jaeger, A. Fielicke, G. von Helden, G. Meijer, M.A. Duncan, Chemical Physics Letters. 392 (2004) 409-414.

[35] D.F. Ogletree, H. Bluhm, E.D. Hebenstreit, M. Salmeron, Nuclear Instruments \& Methods in Physics Research Section a-Accelerators Spectrometers Detectors and Associated Equipment. 601 (2009) 151-160.

[36] M. Salmeron, R. Schlogl, Surface Science Reports. 63 (2008).

[37] C. Rau, C. Liu, A. Schmalzbauer, G. Xing, Physical Review Letters. 57 (1986).

[38] W. Wagner, A. Pruss, Journal of Physical and Chemical Reference Data. 31 (2002). 
[39] M.C. Biesinger, L.W.M. Lau, A.R. Gerson, R.S.C. Smart, Applied Surface Science. 257 (2010).

[40] J.F. Moulder, J. Chastain, Handbook of X-ray Photoelectron Spectroscopy: A Reference Book of Standard Spectra for Identification and Interpretation of XPS Data, Physical Electronics, 1995.

[41] D. Briggs, G. Beamson, Analytical Chemistry. 64 (1992).

[42] K. Andersson, A. Gomez, C. Glover, D. Nordlund, H. Ostrom, T. Schiros, O. Takahashi, H. Ogasawara, L.G.M. Pettersson, A. Nilsson, Surface Science. 585 (2005)

[43] XPS Thickness Solver, K.C. Smith, D.A. Saenz, D. Zemlyanov, A.A. Voevodin, 2012, https://nanohub.org/resources/xpsts

[44] NIST Standard Reference Database 82 Version 1.3 ed., The National Institute of Standards and Technology (NIST), http://www.nist.gov/srd/nist82.cfm.

[45] V. Simic-Milosevic, N. Nilius, H.P. Rust, H.J. Freund, Physical Review B. 77 (2008).

[46] Elettra Trieste, http://ulisse.elettra.trieste.it/services/elements/WebElements.html.

[47] J. Schoiswohl, M. Sock, S. Surnev, M.G. Ramsey, F.P. Netzer, G. Kresse, J.N. Andersen, Surface Science. 555 (2004) 101-117.

[48] C. Grygiel, C. Simon, B. Mercey, W. Prellier, R. Fresard, P. Limelette, Applied Physics Letters. 91 (2007).

[49] M. Abu Haija, S. Guimond, A. Uhl, H. Kuhlenbeck, H.J. Freund, Surface Science. 600 (2006) 1040-1047.

[50] K. Andersson, G. Ketteler, H. Bluhm, S. Yamamoto, H. Ogasawara, L.G.M. Pettersson, M. Salmeron, A. Nilsson, Journal of the American Chemical Society. 130 (2008) 2793-2797.

[51] H. Bluhm, Journal of Electron Spectroscopy and Related Phenomena. 177 (2010) 7184.

[52] S. Yamamoto, H. Bluhm, K. Andersson, G. Ketteler, H. Ogasawara, M. Salmeron, A. Nilsson, Journal of Physics-Condensed Matter. 20 (2008).

[53] D.S. Toledano, P. Metcalf, V.E. Henrich, Surface Science. 472 (2001) 21-32.

[54] N. Missert, R.G. Copeland, Applied Surface Science. 254 (2008) 1972-1976.

[55] E.A. Kroeger, D.I. Sayago, F. Allegretti, M.J. Knight, M. Polcik, W. Unterberger, T.J. Lerotholi, K.A. Hogan, C.L.A. Lamont, M. Cavalleri, K. Hermann, D.P. Woodruff, Surface Science. 602 (2008) 1267-1279. 